\title{
DEMOGRAPHY OF SHORT-TAILED SHREW POPULATIONS LIVING ON POLYCHLORINATED BIPHENYL-CONTAMINATED SITES
}

\author{
RUDY BOONSTRA* and LANNA BOWMAN \\ Division of Life Sciences, University of Toronto at Scarborough, 1265 Military Trail, Scarborough, Ontario M1C 1A4, Canada
}

(Received 9 July 2002; Accepted 18 November 2002)

\begin{abstract}
In ecological risk assessment, a key necessity is to understand how contaminants known to have negative impact on laboratory mammals affect the population demography of mammals living in their natural environment. We examined the demography of six local populations of the short-tailed shrew (Blarina brevicauda) living in eastern deciduous forest palustrine habitat along the Housatonic River (MA, USA) on soils contaminated with a range of polychlorinated biphenyl (PCB) concentrations (1.5-38.3 $\mathrm{ppm}$ ). The objective of the study was to assess whether PCBs adversely affect the population demography of these small mammals living in their natural environment. Blarina were selected for study because they would be expected to readily bioaccumulate PCBs from the soil. Populations were intensively live trapped on 1-ha grids from spring to autumn 2001. There was no relationship between any demographic parameter and PCB soil concentrations. Densities were high (usually exceeding 20/ha, and on two grids exceeded 60/ha in summer); survival was good (typically $60-75 \%$ per $30 \mathrm{~d}$ ); and sex ratio, reproduction rates, growth rates, and body mass were within the ranges reported in the literature. Thus, these shrew populations showed no detectable impact on their population demography from living on PCB-contaminated sites.
\end{abstract}

Keywords-Shrews Contamination Polychlorinated biphenyls Population effects Natural environment

\section{INTRODUCTION}

The short-tailed shrew, Blarina brevicauda is the largest shrew in North America and is one of the most common smallmammal species in the eastern deciduous forests [1]. They are semifossorial mammals, with runways in the top $10 \mathrm{~cm}$ of the soil, and spend little time on the ground surface (for a review of their biology, see [2]). Food appears to be the major limiting factor in woodland habitats. Although Blarina avoid areas with little cover and with extremes in temperature and moisture, specific types of vegetation, cover, temperature, and moisture have little effect on local distribution. They are more common in areas with more than $50 \%$ herbaceous cover. Their high metabolic rate requires that they consume over half their body weight in food daily. Earthworms, slugs, and insects are the major prey items, though spiders, mollusks, and some vertebrates (other shrews, snakes, salamanders, and voles) are also eaten [3]. Thus Blarina's life history, diet, high metabolic rate, and high food consumption rate make it an ideal bioindicator species to assess the ecological risk of bioaccumulative chemicals, such as polychlorinated biphenyls, and their impact on demography in natural populations.

Polychlorinated biphenyls (PCBs) are organochlorines that are persistent, highly lipophilic, and widespread throughout the environment [4]. They bioaccumulate in the food chain and therefore higher trophic level animals have higher potential for exposure. Because PCBs adsorb strongly to organic matter [5] that is eaten by earthworms and these are a major part of the diet of Blarina, PCBs should bioaccumulate readily in Blarina. Indeed, PCBs are known to accumulate in earthworms [6]. Most of the field evidence for bioaccumulation on PCBs in Blarina is suggestive, coming from accidentally contaminated sites [7]. In contrast, the field evidence in European

* To whom correspondence may be addressed (boonstra@utsc.utoronto.ca). shrews is more convincing $[7,8]$. The best evidence of the potential for bioaccumulation in Blarina in North America comes from long-term studies of the organochlorine DDT. Relative to other small-mammal species, the highest DDT concentrations and longest persistence occurred in Blarina populations $[7,9,10]$. However, recent evidence from the Housatonic River [11] indicates that bioaccumulation of PCBs must be occurring in Blarina as well (see Discussion).

Laboratory evidence indicates that PCB contamination can detrimentally affect mammalian physiology [12]. Studies on domestic rodents and on Peromyscus spp. indicate that, under some exposure conditions, PCBs have negative impacts on both growth and reproduction [5,7,13-15]. A critical unknown is the extent to which laboratory toxicity studies and field studies on bioaccumulation can be used to predict PCB-mediated population-level impacts on Blarina in the environment. Laboratory experiments may exaggerate the potential impacts of the PCBs because they employ uniform levels of exposure, whereas in the natural world, the distribution of PCB can be highly patchy. The evidence that the sublethal effects observed in the laboratory alter demography in the field is weak [16]. To date, virtually all field studies on the impact of PCBs on small mammals have focused on voles and various Peromyscus spp., and there were either no or minor negative impacts [16] or impacts were confounded by the presence of other contaminants $[17,18]$. There is thus a critical need for a comprehensive, population-level study of Blarina in an area where PCBs are the primary contaminant and where there are elevated concentrations of PCBs in the soil.

The Housatonic River floodplain provides such a site. It is located in Berkshire County (MA, USA) and was contaminated with PCBs downstream of the General Electric (Fairchild, CT, USA) facility at Pittsfield (MA, USA). Between 1937 and 1977, General Electric used PCBs (primarily Aroclors 1254 and 1260) as an insulating medium in transformer applications 
[19]. Elevated levels of PCBs ( $\geq 1 \mathrm{ppm}$ ) are restricted primarily to the river sediments and to the soils in the 10-year floodplain. In the soils, there is a wide range of PCB concentrations and thus the exposure of mammals may be site dependent.

The goal of our research was to assess the impact of PCB contaminants on natural populations of Blarina exposed to a range of PCB concentrations. Although the terrestrial ecosystems along the Housatonic River have been characterized during previous studies $[19,20]$, only anecdotal information on Blarina was collected. Because laboratory studies have indicated that small-mammal reproduction and growth are particularly sensitive to PCB effects $[5,13,14]$, our goal was to study Blarina populations over one breeding season to examine these parameters and their impacts on demography and population structure.

\section{STUDY GOALS AND DESIGN}

The objective of this study was to live-trap breeding populations of Blarina living on areas contaminated with a range of PCB concentrations in order to compare populations present in areas with high versus low PCB concentrations. The endpoints assessed were demographic parameters that could potentially be affected by PCB exposure-density, survival, rates of reproduction, sex ratio, and growth rates-and these may be modified by site-specific effects such as differences in exposure to flood events and habitat quality. Because no study has examined the impact of PCBs on these demographic parameters in Blarina, we have reviewed findings from other small-mammal species, principally from the laboratory and from one in situ field study [16]. Based on these findings, we hypothesize that, if PCB exposure is negatively affecting Blarina populations, population density would be lower on sites with higher PCB soil concentrations (because of reduced survival and reduced reproduction $[13,15])$, frequency of reproduction would be curtailed and would be exposure dependent $[14,21]$, and body growth would be lower $[13,14]$. Ideally, we would also have liked to quantify the rates of production and survival of young produced on each site, but this was not possible for two reasons. First, young Blarina do not enter traps until they are virtually adult size (at least three-fourths grown [22]). Thus, the source of new animals (on-site reproduction or immigration) cannot be known with confidence. Second, by their nature, floodplains are regularly inundated [23] and thus, over the portion of the breeding season subject to floods, young may not be produced on site. Nevertheless, strategic live trapping during a portion of the breeding season not subject to flooding should permit a rigorous, quantitative assessment of other critical population parameters.

In addition, because previous research indicates no consistent trend on the impact of floods on small-mammal populations, with impact ranging from minor or of short duration [23] to severe [24], we cannot make a definitive hypothesis on the impact of flooding. But in all these studies, the foci of the research were the potentially arboreal Peromycus spp., which could escape by climbing trees. Blarina does not have this option and thus we expected their populations to be markedly reduced, relying on recolonization from high ground. Finally, habitat quality would also affect densities, acting largely through presence of food and to some extent cover [2], and we can expect this would influence our results. We tried to deal with this by having trapping grids that differed only in PCB concentrations but not habitat quality.

Our study was designed to assess Blarina populations dur- ing that portion of the breeding season that was flood free, after a sufficient delay to permit recovery from the major flood event occurring in the early spring after snowmelt. We allowed approximately four to six weeks to elapse after the spring flood before the first trapping session to permit recolonization of the floodplains. Environmental constraints thus determined when the first trapping session occurred. We trapped intensively three times over the flood-free period with a technique designed specifically for Blarina involving multiple checks of the traps during the day to minimize the length of time the animals were in the traps and no overnight trapping (traps were locked open on the last check of the day) to prevent trap-induced mortality.

Our study evaluated Blarina on sites with a wide range of soil PCB concentrations but employed no reference populations on PCB-free floodplains, as previous reconnaissance [20] indicated there are no suitable areas with similar vegetation types and sufficient area within an $80-\mathrm{km}$ radius. Thus, we employed published studies as benchmarks with which to compare our findings.

\section{STUDY SITE}

\section{Grid site selection}

The study took place in the spring, summer, and autumn of 2001 in western Massachusetts along a 16-km reach of the Housatonic River between Pittsfield and Woods Pond (Fig. 1). All potential sites within the 10-year floodplain of the river were explored. Following this exploration, six sites were selected based on PCB concentrations, habitat uniformity, and sufficient area to permit a 1-hectare (ha) trapping grid to be located within each area. Two grid classes were selected, designated as low-PCB grids and high-PCB grids, with three sites in each class. A spatially weighted average PCB concentration was calculated for each grid using the method described by Chow et al. [25] and using soil concentration data collected by the U.S. Environmental Protection Agency (U.S. EPA) and GE (http://www.epa.gov/region01/ge/thesite/restofriver-maps. html) and data from a U.S. EPA CD-ROM _030102_use pa_hr_dbase1.mdb). Only concentrations in the top $15.24 \mathrm{~cm}$ of the soil horizon (where Blarina are active) from sampling points within the trapping grid and a 33-m buffer around the grid were used to obtain these averages. The 33-m buffer around the grid was a conservative estimate of how far Blarina would typically move during their daily activities. In fact, the mean within-trapping session movement of Blarina over the entire study was $11.04 \mathrm{~m} \pm 1.21(n=156)$ ( \pm one standard error of the mean), with males moving significantly longer distances than females $(F=7.19, d f=1,154, p<0.008$; males: $14.15 \pm 1.94, n=74$; females: $8.23 \pm 1.14, n=82$ ). The low-PCB grids had spatial average concentrations ranging between 1.5 and $2.5 \mathrm{ppm}$, and the high-PCB grids had concentrations ranging between 17.6 and $38.3 \mathrm{ppm}$ (Table 1).

All sites were located within the eastern deciduous temperate forest biome in primarily palustrine habitat (as designated on the U.S. EPA habitat classification maps) with portions of two grids (grids 3 and 5, Fig. 1) also including upland habitat. However, differences in habitat did occur, as all highPCB sites were immediately adjacent to the river and subject to increased frequency of flooding and scouring associated with the flooding events whereas all low-PCB sites were on slightly higher ground some distance from the river. Four of our sites overlapped with or were near those of previous smallmammal studies in this area. Grid 1 was in the same area as site 1B used by TechLaw [19, Fig. 3.3.1] and grid 2 was 
adjacent to it ( $\sim 100 \mathrm{~m}$ away). Grid 5 was on the same floodplain forest site used by ChemRisk [20, Fig. 2-3] and by TechLaw [19, site 8, Fig. 3.3.1]. Grid 3 was just downriver of site 3 used by TechLaw [19, Fig. 3.3.1]. The TechLaw [19] study provides a detailed description of the vegetation for their sites and for the general area.

\section{MATERIALS AND METHODS}

\section{Environmental constraints}

Heavy late winter snows in the Pittsfield area resulted in a significant snow pack in early April ( $0.5 \mathrm{~m}$ snow on meadows on April 3, 2001). Snowmelt occurred shortly thereafter and was followed by severe flooding in mid-April (16-17). The flood waters subsided by late April to early May, so we delayed setting up the trapping grids until late May (grid site selection occurred between May 22 and May 24), and the first trapping session took place between May 29 and June 6. A brief flood again occurred in early June, inundating grids 2, 4, 6, most of 3 , and some of 1; grid 5 remained mostly dry. Trapping had been completed on grids 1,2 , and 5 before the flood hit, but the flood prevented trapping on the other three areas. The second (July 16-28) and the third (September 6-24) trapping sessions were conducted over longer periods of time because all grids were trapped.

\section{Live trapping}

All grids had 100 grid points (at 10-m intervals) and covered 1 ha of forest (except for grid 3, which was 1.04 ha), but not all grid points were arranged in a $10 \times 10$ pattern. Grids were fit as efficiently as possible into the section of forest chosen. Grid area included a 5-m-wide area (half the distance between traps) around the perimeter of each grid. Grid setup took approximately $8 \mathrm{~d}$. All grid points were marked by semipermanent, orange surveying 1-m flags, with the proper grid coordinate displayed on each. Fifty Longworth live traps (Penlon, Abingdon, UK) were placed on each grid at every second point, starting at A1. Traps were placed as close to the grid stake as possible where sufficient protection from the elements was provided. Fallen bark or ferns were placed on top of the traps to provide more shade. All traps were baited with crimped oats.

Each grid was prebaited for $1 \mathrm{~d}$ prior to trapping to habituate small mammals to the traps. During the prebaiting period, traps were locked open and a small amount of crimped oats was placed in the nest box. During the trapping session, traps were set at first light (in spring and summer, this was completed by $0600 \mathrm{~h}$; in autumn, this was completed by $0700 \mathrm{~h}$ because of declining day length) and then checked as frequently as possible (four times a day in spring and summer [at 0900, 1200, 1500 , and $1800 \mathrm{~h}$ ] and three times in autumn [at 1000, 1330, and $1700 \mathrm{~h}])$. At the end of each day, the traps were locked open to prevent capture of animals overnight. Over the course of the study, we planned to trap each grid three times (in spring, summer, and autumn), but because of severe flooding part way through the spring session, only three grids were trapped three times and the other three were trapped twice. During each trapping session, each of the grids was trapped for 3 consecutive days. We attempted to trap two grids simultaneously, but weather and logistics prevented this on occasion. Traps were removed at the end of the third day, scraped out, rebaited, locked open and placed on the next two grids for prebaiting. This was repeated until all six grids were trapped. Traps used
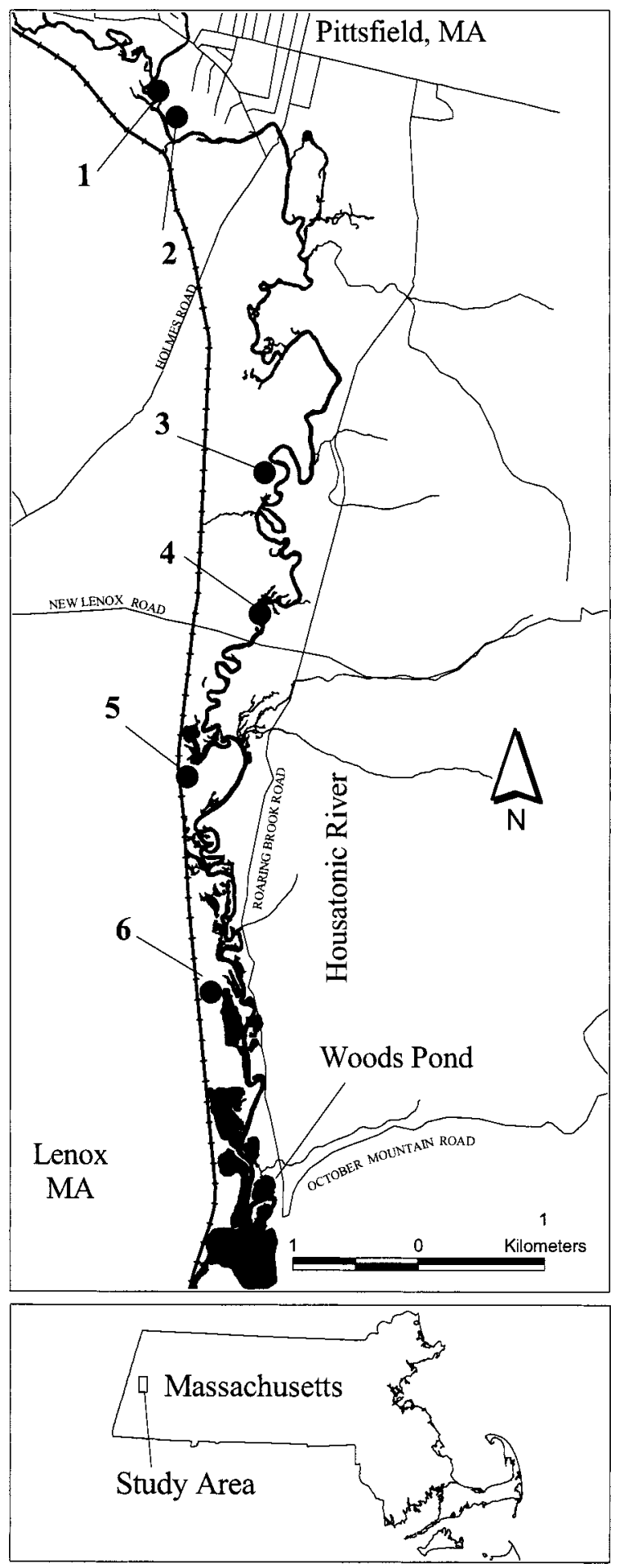

Fig. 1. Location of the six trapping grids along the Housatonic River between Pittsfield and Woods Pond, Massachusetts, USA.

on high-PCB contaminated grids were used only on other highPCB contaminated grids, and likewise for low-PCB contaminated grids.

On first capture, all the short-tailed shrews were marked with a unique number by toeclipping (no more than two toes on each of the hind feet) and, on first capture in each trapping session, sex, sexual condition (females lactating or not; males breeding or not), mass, and location were obtained. Females were identified by the presence of nipple scars. Lactating fe- 
Table 1. Spatially weighted average concentrations of polychlorinated biphenyls in the areas where the trapping grids were placed. Only sediment sample points within the trapping grids and within a 33-m buffer were included. Only concentrations collected within the top $15.24 \mathrm{~cm}$ of the soil horizon were used in calculating these weighted averages

\begin{tabular}{lcc}
\hline Grid & $\begin{array}{c}\text { Concentration } \\
(\mathrm{ppm})\end{array}$ & $\begin{array}{c}\text { Number of } \\
\text { soil samples }\end{array}$ \\
\hline 1 & 33.5 & 53 \\
2 & 2.5 & 3 \\
3 & 17.6 & 5 \\
4 & 38.3 & 14 \\
5 & 2.2 & 6 \\
6 & 1.5 & 4 \\
\hline
\end{tabular}

males were distinguished from nonlactating females by their prominent nipples sticking up beyond the level of the fur line and slightly lighter colored skin surrounding the nipple. Females were identified as pregnant when they were pear shaped. If no nipple scars were found, the animal was identified as a male, and this was confirmed by extracting the penis by gently pressing down into the abdomen and pushing back toward the tail. Although males have no scrotum, when breeding, their enlarged testes are readily evident as prominent protrusions in the inguinal area. If not obvious, we would gently press on the rear abdominal area to force the testes toward the tail to determine testes size. We did not attempt to distinguish overwintered animals from young of the year for two reasons. First, because we did not start trapping until late May, a pure overwintered cohort could not be determined on the basis of animal mass or pelage condition. By that time, the population could have already been breeding for at least two months and for up to four months if the late winter conditions prevailed that Christian [26] found in New York (USA). Second, young of the year do not enter traps until they are at least three-fourths grown [22] and only five of the 240 new animals caught weighed less than $15 \mathrm{~g}$. Thus, it was not possible to obtain recruitment of young to the population as a function of the number of adults present. To obtain an index of how far shrews moved during their daily activities (foraging, territorial defense, etc.), we calculated the maximum distance moved between capture locations within a trapping session.

\section{Population analysis}

Population estimates and standard errors were obtained using a mark-recapture heterogeneity (jackknife) model [27] from the program Capture [28]. This is a closed-population estimator and thus assumes that there is no mortality and no immigration or emigration during the sampling period. It is a robust method for estimating population size and is recommended by Menkens and Anderson [29]. The standard errors resulting from these estimates are not equivalent to sampling error, and thus power analyses to compare population estimates could not be done.

Survival was assessed in two ways. If an animal disappeared from the trapping grid, we could not know if it had died or emigrated and thus mortality was equated with disappearance. In the first analysis, survival rates were measured by direct enumeration of marked animals [30]. These rates were calculated as the percentage of animals recaptured at time 2 that were released at time 1 and are expressed as the minimum survival rates per $30 \mathrm{~d}$ to permit comparisons with other live-trapping studies of Blarina. The true survival rate should never be less than these rates. In the second analysis, a logistic regression was carried out for the period between mid-July and September. A similar analysis was not conducted between late May to early June and mid-July because of the possible negative effects following flooding during the first trapping session. Survival was determined between trapping sessions 2 and 3 based on recapture. These results were recorded for each animal as a binary datum (recaptured/surviving $=1$, disappearing $=0$ ). This technique converted binary data from individuals into probability values by fitting a logistic curve through available points [31]. The analysis involved a logistic regression with the factors grid and sex as the main effects. Animals were included in the analysis if they had been released from the trap in session 2 in a healthy condition. On several of the days in that session, heavy rains resulted in some animals becoming wet in the traps, suffering the effects of hypothermia, and, though none were dead when they were removed from the traps, some were very weak. We noted these animals and removed them from the analysis.

To assess reproduction, animals were defined as potentially being in breeding condition based on their body mass. In males, all animals weighing $\leq 19 \mathrm{~g}$ were excluded from the analysis because only three of 42 males less than or equal to this weight were classified as being in breeding condition (enlarged testes). In females, no animal $<18 \mathrm{~g}$ was found to be lactating, and thus all animals $\geq 18 \mathrm{~g}$ were included as potentially breeding. Because only three females could be positively identified as pregnant, this was a poor index to discriminate among treatments. Differences among trapping sessions, grids, and areas (high- vs low-PCB concentrations, as above) were analyzed by logistic regression. The reproductive status for each animal was recorded as a binary datum (reproductive $=1$, nonreproductive $=2$ ).

To assess how weight dynamics were affected on our trapping grids, we carried out two analyses. First, instantaneous growth rates per day were calculated for all animals caught in more than one trapping session. Instantaneous growth rates are simple conversions of finite rates [32] and are used widely for small mammals [30]. Because so few animals caught in session 1 were caught again in session 2, these data were not used and the analysis was carried out only on growth rates between sessions 2 and 3. The analysis required an analysis of covariance, with weight as the covariate, as younger animals grow more rapidly than older ones. Second, differences in mean body weights among the populations were compared. However, this latter analysis is less robust than the first one because some animals were represented in more than one trapping session (i.e., the samples were not strictly independent). Again, only trapping sessions 2 and 3 were included in the analysis because sample size was too small for session 1 .

\section{Statistical analysis}

All statistical tests were performed according to procedures in Zar [33] and Sokal and Rohlf [34]. All analyses of variances (ANOVAs) and post hoc tests (Tukey-Kramer) were performed with Statsview [35]. In general, the statistical approach involved three analyses. First, because Blarina populations on our trapping grids were exposed to a gradient of PCB concentrations (range 1.5-38.3 ppm; Table 1), we assessed exposure-response relationships for demographic parameters using simple correlation analyses. Second, grids were classified as to whether they had low $(<2.6 \mathrm{ppm})$ or high $(>17.5 \mathrm{ppm})$ PCB soil concentrations and each grid was treated as a replicate 
Table 2. Total number of different individuals caught between May and September 2001 in the Housatonic River, Massachusetts, USA, study area. Traps were set for $3 \mathrm{~d}$ in each trapping session during daylight hours only

\begin{tabular}{|c|c|c|c|c|c|c|c|c|c|c|}
\hline Grid & $\begin{array}{l}\text { Short-tailed } \\
\text { shrew }\end{array}$ & $\begin{array}{l}\text { Meadow } \\
\text { vole }\end{array}$ & $\begin{array}{l}\text { Pine } \\
\text { vole }\end{array}$ & $\begin{array}{l}\text { White-footed } \\
\text { mouse }\end{array}$ & $\begin{array}{l}\text { Southern } \\
\text { red-backed } \\
\text { vole }\end{array}$ & $\begin{array}{l}\text { Eastern } \\
\text { chipmunk }\end{array}$ & $\begin{array}{l}\text { Short-tailed } \\
\text { weasel }\end{array}$ & $\begin{array}{l}\text { Red } \\
\text { squirrel }\end{array}$ & $\begin{array}{c}\text { Meadow } \\
\text { jumping } \\
\text { mouse }\end{array}$ & Total \\
\hline $1^{\mathrm{a}}$ & 60 & 50 & 0 & 13 & 1 & 10 & 0 & 0 & 0 & 134 \\
\hline $2^{\mathrm{a}}$ & 53 & 21 & 0 & 13 & 1 & 6 & 1 & 0 & 1 & 96 \\
\hline $3^{b}$ & 28 & 1 & 0 & 1 & 2 & 13 & 0 & 0 & 4 & 49 \\
\hline $4^{b}$ & 38 & 79 & 0 & 1 & 0 & 4 & 1 & 0 & 0 & 123 \\
\hline $5^{\mathrm{a}}$ & 33 & 0 & 3 & 2 & 1 & 0 & 0 & 0 & 0 & 39 \\
\hline $6^{\mathrm{b}}$ & 28 & 10 & 3 & 0 & 1 & 4 & 0 & 1 & 2 & 49 \\
\hline Total & 240 & 161 & 6 & 30 & 6 & 37 & 2 & 1 & 7 & 490 \\
\hline
\end{tabular}

a Trapped in May-June, July and September.

${ }^{\mathrm{b}}$ Trapped in July and September only because flooding prevented trapping in May-June.

of these two categories. Third, we assessed whether there was an area effect (two northern grids vs the four southern grids) because the vegetation and undergrowth was more lush in the northern grids and each grid was treated as a replicate of these two categories. Binary data (survival and breeding condition in males and females) were analyzed by logistic regression using log-likelihood ratios to test for effects as implemented in the program JMP [36]. Power analyses were performed by Statsview [34] and by PASS Ver 6.0 [37]. All means are expressed as \pm one standard error of the means.

\section{RESULTS}

\section{Species captured}

Nine small-mammal species were caught along the Housatonic River during the summer of 2001 (Table 2), but only one, the short-tailed shrew (Blarina brevicauda), was ubiquitous and abundant on all grids ( $\geq 28$ different individuals). The meadow vole (Microtus pennsylvanicus) was reasonably common on four grids ( $\geq 10$ different individuals) and particularly abundant on grid 4 (Fig. 1), as it had plentiful grass cover in certain sections. Five species were caught less frequently, including the white-footed mouse (Peromyscus leucopus), the southern red-backed vole (Clethrionomys gapperi), the meadow jumping mouse (Zapus hudsonius), the pine vole (Microtus pinetorum), and the eastern chipmunk (Tamias striatus). Two short-tailed weasels and one red squirrel were also caught. Because our trapping was restricted to the daylight hours, our sampling technique did not target species that are largely nocturnal-the white-footed mouse, the southern redbacked vole, and the meadow jumping mouse, and thus little can be said about their actual presence on the grids. Eastern chipmunks are diurnal and were found at low abundance on five grids.

\section{Population changes of Blarina}

Population densities per hectare of the short-tailed shrew on the six grids ranged from a low of eight animals in May to June to a high of 67 in July (both estimates from grid 1) (Fig. 2). There were two clusters of grids with respect to density changes - the two northern grids showed pronounced population fluctuations, whereas the four southern ones remained remarkably constant. The two grids nearest Pittsfield (grids 1 and 2, Fig. 1) fluctuated in parallel over the summer, increasing three to eight times from May to June to July and then declining 42 to $57 \%$ by mid-September. The only grid of the other four that was trapped at all three times (grid 5) remained constant over time (range 19-22); in late spring, it had slightly higher densities than the northern grids, showed no midsummer increase, and showed no autumn decline. Though we have only two estimates for the other three grids, all remained remarkably constant, increasing only 4 to $22 \%$ from summer to autumn.

To examine whether there was a negative relationship between PCB concentrations (Table 1) and population density (Fig. 2), we used simple correlation analysis. We found no relationship in either summer $(r=0.30, n=6, p=0.56$, power $=0.09)$ or autumn $(r=0.54, n=6, p=0.27$, power $=0.20)$. A spring relationship could not be calculated because only three grids were trapped. When the trapping grids were split into high- and low-PCB concentrations, a repeated measures ANOVA on trapping sessions 2 and 3 also showed no evidence of an effect of PCB concentrations $(F=0.43, d f=$ $1,4, p=0.55)$, but power was low (0.08) because of low sample size and high variance among the grids. To assess the importance of an area effect independent of PCB concentrations, the grids (Fig. 1) were separated into the two northern grids ( 1 and 2 ) and the four southern grids (3-6), and a repeated measures ANOVA was performed on trapping sessions 2 and 3. The area effect was significant $(F=19.69, d f=1,4, p=$ $0.01)$ and power was high (0.91). Hence, area, not differences

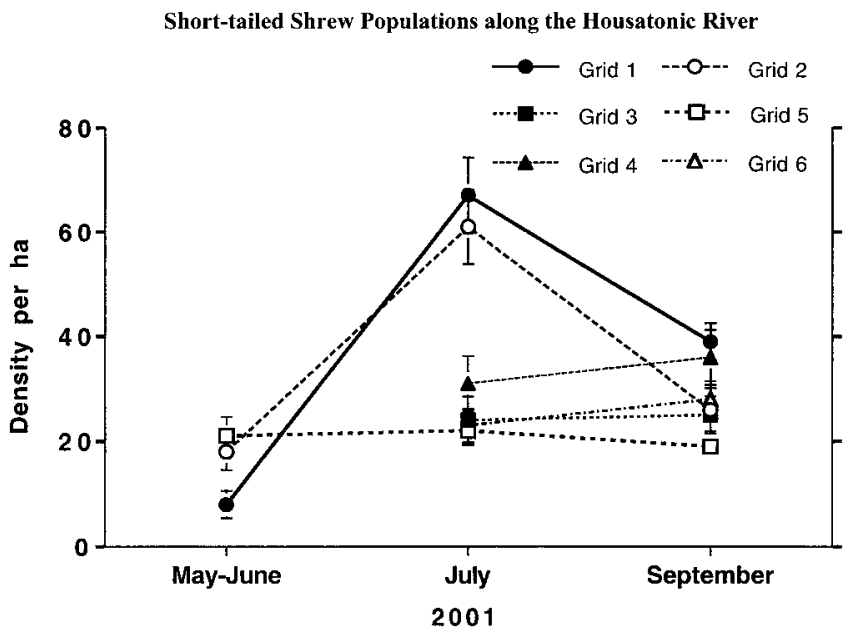

Fig. 2. Population densities ( \pm one standard error of the mean) per hectare of Blarina brevicauda in 2001 on six live-trapping grids along the Housatonic River (MA, USA) between Pittsfield and Woods Pond. Three of the grids (solid symbols) were located on sites with high polychlorinated biphenyl (PCB) concentrations and three (open symbols) were on sites with low PCB concentrations. Points without error bars have very narrow standard error values obscured by the point itself. 
Table 3. Survival of Blarina brevicauda per $30 \mathrm{~d}$ on six sites adjacent to the Housatonic River downstream of Pittsfield, Massachusetts, USA. Note that a survival rate of $75 \%$ per $30 \mathrm{~d}$ means that half the population disappears every $72.3 \mathrm{~d}$

\begin{tabular}{|c|c|c|c|c|c|c|c|c|}
\hline \multirow[b]{4}{*}{ Grid } & \multicolumn{8}{|c|}{ Trapping session } \\
\hline & \multicolumn{4}{|c|}{ May-July } & \multicolumn{4}{|c|}{ July-September } \\
\hline & \multicolumn{2}{|c|}{ Males } & \multicolumn{2}{|c|}{ Females } & \multicolumn{2}{|c|}{ Males } & \multicolumn{2}{|c|}{ Females } \\
\hline & $\%$ & $n$ & $\%$ & $n$ & $\%$ & $n$ & $\%$ & $n$ \\
\hline 1 & 0.0 & 1 & 80.8 & 3 & 74.5 & 21 & 67.7 & 17 \\
\hline 2 & 76.4 & 5 & 33.4 & 8 & 63.9 & 19 & 53.1 & 17 \\
\hline 3 & & & & & 100.0 & 1 & 63.5 & 14 \\
\hline 4 & & & & & 38.6 & 13 & 40.5 & 6 \\
\hline 5 & 64.4 & 10 & 55.7 & 5 & 79.5 & 11 & 74.2 & 9 \\
\hline 6 & & & & & 76.2 & 8 & 83.2 & 11 \\
\hline
\end{tabular}

in PCB concentrations, explained most of the differences among the grids in population estimates.

\section{Survival}

The 30-d survival estimates between sessions 1 and 2 (Table 3) were variable, being affected by small sample size and probably by the early June flood event. Even though animals were forced to move away from the grids (Fig. 1) following the flood, some showed high site fidelity and were subsequently caught again in the second trapping session on the same grid as during the first trapping session. On grid 1, two females, and on grid 2, three males and one female were caught before (May-June) and after (July) the flood. Grid 5 experienced minimal effects of this flood event, and five males and two females were caught both times. A few animals were caught on these grids in all three trapping sessions (one female on grid 2, one female and five males on grid 5). Between sessions 2 and 3 , there were marked differences in survival among grids, with that on grids 1,5 , and 6 being the highest and that on grid 4 the lowest (Table 3). On the former grids, animals were living almost three times as long as on the latter grid, with half surviving about $72 \mathrm{~d}$ on the former grids versus only about $22 \mathrm{~d}$ on grid 4 . A simple correlation of population size on PCB levels on the grids showed no significant relationship between PCB concentrations and survival from summer to autumn for either males $(r=-0.62, n=5, p=0.27$, power $=0.20$; grid 3 was excluded because only one male was caught in summer) or females $(r=-0.58, n=6, p=$ 0.23 , power $=0.23$ ).

In the logistic regression analysis of survival, a two-factor model (grid and sex) was used. There was a significant difference in survival among grids $\left(\chi^{2}=15.62, d f=5, p=\right.$ $0.008)$, no difference between the sexes $\left(\chi^{2}=1.36, d f=1\right.$, $p=0.24)$, and no interaction effect $\left(\chi^{2}=2.07, d f=5, p=\right.$ 0.84 ). Thus, males and females showed similar survival from midsummer to autumn within a trapping grid. To evaluate whether the differences among grids were the result of differences in PCB concentrations, grids were pooled and classified as having high or low PCB concentrations as defined above. There was no difference in survival between high- or low-PCB sites $\left(\chi^{2}=1.03, d f=1, p=0.31\right)$, and thus the grid effect was related to factors other than PCB concentrations.

\section{Sex ratio}

Changes in the sex ratio may give insight into the breeding structure of the population and whether there are differential effects of PCBs on one sex (Table 4). In trapping session 1, there was no difference among the grids $\left(G^{2}=0.67, d f=2\right.$, $p=0.71)$ with $35.5 \%(n=33)$ of the animals being male. In session 2 , there was a significant difference among grids $\left(G^{2}\right.$ $=15.76, d f=5, p=0.008)$, but this was a result primarily of a strongly skewed sex ratio on grid 3 (only 1 of 15 animals was a male). When this grid was excluded, there was no difference among grids in session $2\left(G^{2}=4.09, d f=2, p=\right.$ $0.39)$, with $48.6 \%(n=138)$ being male. In session 3 , there was also no difference among grids $\left(G^{2}=7.63, d f=5, p=\right.$ $0.18)$, with $40.4 \%(n=136)$ being male. However, for sessions 2 and 3 , grids 1 and 2 had 10 to $20 \%$ more males than the other grids (Table 4). As with the population analysis, the data from the two northern grids ( 1 and 2 ) were pooled and compared with that from the pooled sex ratio on the other four grids. In both cases, there was a significant difference between these two clusters (session 2: $G^{2}=8.03, d f=1, p=0.005$, with $55.0 \%$ being male on the northern grids and $32.4 \%$ being male on the four southern grids; session $3: G^{2}=5.52, d f=$ $1, p=0.02$, with values being 52.8 and $32.5 \%$, respectively). To assess whether PCB concentrations affected sex ratio, only sessions 2 and 3 were examined. A simple correlation analysis of sex ratio on $\mathrm{PCB}$ concentrations in the grids showed no significant relationship between PCB concentrations and sex ratio in either summer $(r=-0.22, n=6, p=0.68$, power $=0.07)$ or autumn $(r=0.14, n=6, p=0.79$, power $=0.06)$. When the grids were pooled by PCB class (high vs low), there was again no evidence of a difference in sex ratio as a function of PCB concentrations (session 2: $G^{2}=1.89, d f=1, p=$ 0.17 ; session 3: $G^{2}=0.002, d f=1, p=0.96$ ). Thus, there were area effects on sex ratio but no effect of PCB concentrations.

Table 4. Sex ratio of Blarina brevicauda on the six trapping grids over the summer of 2001. Sex ratio is expressed as the percentage of males $(n=$ total sample size $)$

\begin{tabular}{|c|c|c|c|c|c|c|}
\hline \multirow[b]{2}{*}{ Grid } & \multicolumn{2}{|c|}{ May-June } & \multicolumn{2}{|c|}{ July } & \multicolumn{2}{|c|}{ September } \\
\hline & $\%$ & $n$ & $\%$ & $n$ & $\%$ & $n$ \\
\hline 1 & 20.0 & 5 & 53.4 & 43 & 52.9 & 34 \\
\hline 2 & 38.5 & 13 & 56.8 & 37 & 52.6 & 19 \\
\hline 3 & & & 6.7 & 15 & 20.0 & 20 \\
\hline 4 & & & 31.6 & 19 & 39.1 & 23 \\
\hline 5 & 33.3 & 15 & 45.0 & 20 & 35.3 & 17 \\
\hline 6 & & & 42.1 & 19 & 34.8 & 23 \\
\hline
\end{tabular}


Table 5. Mean body masses \pm 1 SEM of Blarina brevicauda on six grids along the Housatonic River between Pittsfield and Woods Pond, Massachusetts, USA. Sample sizes in parentheses

\begin{tabular}{|c|c|c|c|c|c|c|}
\hline \multirow[b]{2}{*}{ Grid } & \multicolumn{3}{|c|}{ Males } & \multicolumn{3}{|c|}{ Females } \\
\hline & May-June & July & September & May-June & July & September \\
\hline 1 & 24.0 & $23.4 \pm 0.6(23)$ & $23.9 \pm 1.6(18)$ & $19.2 \pm 1.6(4)$ & $20.4 \pm 0.6(21)$ & $21.1 \pm 0.5$ \\
\hline 2 & $21.2 \pm 2.7(5)$ & $21.8 \pm 0.6(21)$ & $22.8 \pm 0.6(10)$ & $21.0 \pm 1.6(9)$ & $20.0 \pm 0.7(16)$ & $21.3 \pm 0.8(9)$ \\
\hline 3 & & 19.0 & $19.8 \pm 0.6(4)$ & & $18.7 \pm 0.9(14)$ & $19.0 \pm 0.4(16)$ \\
\hline 4 & & $22.0 \pm 0.7(13)$ & $21.8 \pm 0.6(9)$ & & $21.5 \pm 1.2(6)$ & $19.5 \pm 0.8$ \\
\hline 5 & $18.5 \pm 1.0(10)$ & $19.6 \pm 0.6(9)$ & $17.3 \pm 0.6(10)$ & $18.2 \pm 2.1$ & $18.2 \pm 1.0(9)$ & $18.3 \pm 1.3(6)$ \\
\hline 6 & & $20.8 \pm 1.2(8)$ & $19.5 \pm 0.5(8)$ & & $19.8 \pm 1.1(11)$ & $19.3 \pm 0.5(15)$ \\
\hline
\end{tabular}

\section{Reproduction}

Reproductive parameters are expected to show strong seasonal effects and may also be affected by PCB concentrations in the environment. In males, it was not possible to carry out two-way logistic regressions using grids (six grids) and trapping sessions (two or three sessions, depending on whether the first was excluded) as factors because of insufficient degrees of freedom. In addition, simply assessing whether there were grid effects without considering seasonal changes made no biological sense (there were no simple grid effects; $\chi^{2}=$ $7.73, d f=5, p=0.17$ ). Thus, the most robust analysis involved a two-factor logistic regression involving trapping session versus PCB level (high and low). There was a strong session effect $\left(\chi^{2}=62.25, d f=2, p<0.0001\right)$ but no evidence of a PCB effect $\left(\chi^{2}=0.0\right)$ or an interaction effect $\left(\chi^{2}=3.95, d f\right.$ $=2, p=0.14)$. In trapping sessions 1,2 , and $3,31.2 \%(n=$ $16), 61.3 \%(n=75)$, and $5 \%(n=60)$, respectively, of the males were in breeding condition. Thus, changes in season but not differences in PCB concentrations explained the pronounced changes in male reproductive intensity.

In females, a similar analysis was carried out. There were no simple grid effects $\left(\chi^{2}=8.50, d f=5, p=0.13\right)$. There was a strong session effect $\left(\chi^{2}=22.52, d f=2, p<0.0001\right)$ but no PCB effect $\left(\chi^{2}=0.22, d f=1, p=0.64\right)$ and no interaction effect $\left(\chi^{2}=4.04, d f=2, p=0.09\right)$. In trapping sessions 1,2 , and 3, 75\% $(n=12), 39.7 \%(n=58)$, and $12.3 \%$ $(n=65)$, respectively, of the females were lactating. Thus, changes with season but not differences in PCB concentrations explained the pronounced changes in female reproductive intensity.

\section{Body mass dynamics}

Growth and body mass should reflect environmental conditions. In males, there was a significant effect of body weight on growth rate $(F=9.66, d f=1,21, p=0.005$, power $=$ $0.86)$, no grid effect $(F=1.03, d f=4,21, p=0.41$, power $=0.26$; grid 3 was deleted because only one male was captured in both trapping sessions), and no interaction effect $(F=1.02$, $d f=4,21, p=0.42$, power $=0.26)$. Thus, as expected, smaller males grow faster than larger ones, but grids did not differ in growth rates. To assess whether there was an area effect on growth rate, males were pooled based on where they were living (i.e., the northern two grids vs the southern four grids, as explained above) and on PCB concentrations. Again, there was a significant effect of body weight on growth rate $(F=$ $10.60, d f=1,24, p=0.003$, power $=0.89)$ but no $\mathrm{PCB}$ effect $(F=1.09, d f=1,24, p=0.31$, power $=0.16)$ or area effect $(F=0.26, d f=1,24, p=0.61$, power $=0.08)$; and all interaction effects were not significant. In females, there was a significant effect of body weight on growth rate $(F=$
4.88, $d f=1,21, p=0.04$, power $=0.55)$, no grid effect $(F$ $=0.35, d f=4,21, p=0.84$, power $=0.11$; grid 4 [Fig. 1] was not included because only one female was captured in both trapping sessions), and no interaction effect $(F=0.28$ $d f=4,21, p=0.88$, power $=0.10)$. In the pooled analysis, all effects were nonsignificant (body wt: $F=3.41, d f=1$, $24, p=0.08$, power $=0.41$ PCB: $F=1.78, d f=1,24, p$ $=0.19$, power $=0.23$; area: $F=3.14, d f=1,24, p=0.09$, power $=0.41$; all interaction effects nonsignificant). Thus, small animals grow more rapidly than large ones, but there is no evidence in either males or females of an area effect or of a negative effect of PCB levels.

Table 5 gives the mean body weights for all grids and trapping sessions. There was no relationship between PCB concentrations on a grid and body mass in either males (summer: $r=0.73, n=5, p=0.16$, power $=0.28$; grid 3 excluded because of low sample size; autumn: $r=0.57, n=6, p=$ 0.24 , power $=0.24$ ) or females (summer: $r=0.67, n=6, p$ $=0.15$, power $=0.33$; autumn: $r=0.22, n=6, p=0.67$, power $=0.07)$. To reduce this complexity further, animals were pooled (sessions 2 and 3 only) based on where they were living (i.e., the northern two grids vs the southern four grids) and PCB level, and a two-way ANOVA was carried out. In males, there was a significant area effect $(F=36.84, d f=1,130, p$ $<0.0001)$, a significant PCB effect $(F=20.00, d f=1,130$, $p<0.0001)$, and no interaction effect $(F=0.75, d f=1,130$, $p=0.39)$. In females, there was also a significant area effect $(F=9.75, d f=1,149, p=0.002)$, but no PCB effect $(F=$ $0.41, d f=1,149, p=0.52)$ and no interaction effect $(F=$ $0.005, d f=1,149, p=0.94)$. The significant effects were that males and females in the northern area weighed more than those in the southern area and that males, but not females, weighed more on high-PCB sites.

\section{DISCUSSION}

We tested the hypothesis that the population characteristics of Blarina living on more highly contaminated PCB sites should be more negatively affected than of Blarina living on less contaminated PCB sites. Our results provide no support for this hypothesis. There was no discernible effect of PCB level on population density (Fig. 2), survival (Table 3), sex ratio (Table 4), reproduction, or growth. There was evidence of a PCB effect on mass in males (Table 5) but not in females. However, for the latter result, the males on more highly contaminated sites weighed more, not less, than those on less contaminated sites. This is the opposite of expectations given the results of other studies [13]. The correlation analysis between the above parameters and the degree of exposure to PCBs provided no evidence of a relationship between them; all correlations were nonsignificant and direction of the rela- 
tionship in all cases but survival and male sex ratio were positive, not negative.

Our population study assumed that Blarina living on PCBcontaminated areas would carry PCB burdens reflective of the areas in which they were living and hence that differential soil levels should result in differential burdens. This assumption was validated by U.S. EPA research [11] conducted in 1999 (August 30-September 3) in the same section of the Housatonic River floodplain as our study. The U.S. EPA study examined three sites with average soil PCB concentrations (ppm) of 1.06 ( $n=21$ soil samples), $30.94(n=14)$, and 41.87 ( $n$ $=13$ ) and found average Blarina tissue concentrations (ppm) of $7.01(n=4$ Blarina), $113.0(n=10)$, and $92.5(n=10)$, respectively, for these same sites. Thus, there was a strong positive relationship between PCB soil concentrations and Blarina tissue burdens, indicating that site-specific bioaccumulation is occurring. The literature indicates that body burdens above 10 ppm (i.e., $10 \mathrm{mg} / \mathrm{kg}$ ) [7] have been linked with physiological impairment.

Three other lines of evidence from our population study are also consistent with the above assumption. First, we observed high site fidelity on the three sites trapped both before and after the late spring flood; second, we found restricted movement distances within a trapping session; and third, we observed no movement between grids 1 and 2 even though they were only about $100 \mathrm{~m}$ apart (Fig. 1). These lines of evidence indicate that our assumption is valid and that exposure of shrews should directly reflect the local area where they were living and being trapped, an assumption confirmed by the U.S. EPA data. Thus, we believe it is reasonable to conclude from our results that PCB exposure had no negative effects on the population characteristics we were able to measure.

Seasonal flooding and movement of animals between sites complicate the interpretations of some of our findings. Spring flooding along riverine habitats is a common yearly event in the eastern United States [23] and has been a constant feature in the landscape of New England at least from the period of European colonization onward [38]. Previous studies have suggested that severe flooding lasting several weeks can cause drastic reductions in small-mammal populations that then recover slowly by immigration from surrounding areas [reviewed in 23]. However, Batzli [23] found that, in the white-footed mouse, which can climb trees, adult survival was not affected by flood events, though successful reproduction declined. In contrast, Blarina does not climb trees and hence would have to leave flooded areas. Flooding in mid-April lasted about two to three weeks and would have resulted in emigration of Blarina away from the flooded sites. The flood in late May to early June 2001 was of much shorter duration (several days) but did result in our inability to trap three of the grids and also resulted in animals on grid 2 (Fig. 1) and possibly some of the Blarina on grid 1 having to disperse away temporarily. The flooding events in 2001 did prevent us from obtaining direct measures of on-site reproduction. However, other measures (density, intensity of reproduction, survival, sex ratio, growth and body wt dynamics) are robust and should give insight into the potential effects of PCB exposures on Blarina population characteristics.

It is also possible that we were sampling a transitory population of animals that failed to take up residence and thus failed to be exposed to local conditions for any length of time. Such conditions seem to prevail on grid 4 (Fig. 1), where survival between sessions 2 and 3 was low (Table 3 ), but density in each session was high (Fig. 1). Grid 4 had the highest number of meadow voles of any of the grids (Table 2), which was probably a direct consequence of dense patches of grass cover along the river. Thus, the Blarina populations on this grid may have been more transitory because of lower habitat quality. Large-scale immigration is likely to be the main explanation for the eightfold increase in numbers seen on grid 1 between sessions 1 and 2 (Fig. 2). However, survival was high thereafter, indicating that many of these animals became residents. It is most probable that grid 1 had not yet fully recovered from the severe flood event of mid-April to early May prior to the first trapping session. There are a number of lines of evidence to rule out continuous dispersal for most of our populations after the last flood event. There was no record of any dispersal between grids 1 and 2, even though they were only $100 \mathrm{~m}$ apart at the closest point. In addition, high survival on many of the grids (Table 3) indicates that the animals were taking up residence and remaining on the trapping grids. This corroborates the conclusions of Platt [39] that these animals are territorial and hence strongly attached to a particular site. Thus, we do not think these caveats compromise the conclusions of our study.

We have evaluated whether the findings of our study are comparable with results of other published population studies on Blarina and other small-mammal species. Density estimates of Blarina vary enormously as a function of habitat, ranging from 4.4 to $14.5 /$ ha in forests [2] to 2.5 to 25.6 /ha in grasslands $[2,22]$. The highest number ever recorded during an 18-year period in Illinois (USA) grassland [40] was 54/ha. In general, we recorded consistently higher densities in summer and autumn than any of the studies carried out in forested habitats, and the densities in our grids usually exceeded those from studies carried out in grassland habitats as well. On our two northern grids (1 and 2, Fig. 1), we recorded the highest densities ( $>60 /$ ha in July) ever reported in the literature. We attribute these high densities to our trapping technique, resulting in our density estimates being less confounded by high trapping-induced artifacts caused by mortality (e.g., $42.2 \%$ were found dead in the study by Getz [40]). Moreover, if the ChemRisk [20] population estimates of the white-footed mouse (density of 16/ha) and the southern red-backed vole (8.7/ha) on the grid 5 forested site are reasonably accurate, then our estimates of Blarina densities for this same site (which had the lowest densities of all our sites) still exceeded the estimates for those other individual species estimates (Fig. 1). In the floodplains of Illinois, Batzli [23] found densities of the white-footed mouse (10-20/ha in late summer) that were similar to those of the ChemRisk study. Thus, Blarina is clearly a very major component of the small-mammal community on the Housatonic floodplain. Our high densities and the lack of a differential PCB effect between high- and low-PCB sites support the argument that the effects of PCB concentrations have not constrained Blarina populations in the 10-year floodplain.

There are very few survival estimates for Blarina from other studies, and all of these are confounded by overnight trapping. Nonetheless, estimates from these studies will be used to compare with ours to give lower limits of what animals may experience in other settings. It is important to reiterate that all survival estimates include both on-site mortality and from-site dispersal, and live-trapping studies cannot distinguish between them. Yahner [41] live-trapped shelterbelts in 
Minnesota (USA) for two years and found monthly survival rates of $71 \%$, with no change over the year. Getz [40] found that monthly survival ranged from an average of $33.4 \%$ per month in alfalfa fields to $47.5 \%$ in bluegrass fields. Most of our estimates are at least as high as those seen by Yahner [41] and up to twice those seen by Getz (Table 3). Our most robust spring estimate (given lack of potential flood impacts) comes from grid 5 (Fig. 1), and these are about 15\% less than the late summer estimates of 74 to $80 \%$ for this grid. Grid 4 clearly is an outlier in the late summer, with survival being $20 \%$ lower than on almost all the other grids. However, this reduced survival is not associated with PCB concentrations, as discussed above. Rather, this is likely to be indicative of high dispersal through the site and short residency in it, probably related to habitat-specific characteristics of the site. Thus, in general, our shrew populations show high monthly survival, though there is grid-to-grid variability, but there is no evidence that this variability can be explained by differences in PCB concentrations among the grids.

Unequal sex ratios are common in studies on Blarina, with many reporting more males than females $[2,40,42]$. In contrast, our results in session 1 were biased against males (38\%), and thereafter on the four southern grids (Fig. 1), sex ratios were always less than $45 \%$, with values of less than $40 \%$ being typical (Table 4). However, the two northern grids both were slightly biased in favor of males in sessions 2 and 3, being $10 \%$ higher than either of the other grids. Clearly, there are site-specific differences, but these differences were not related to differences in survival (Table 3) or PCB concentrations (Table 1).

Reproduction of Blarina on the floodplain was largely restricted to spring and summer, tapering off in autumn. The small number of obviously pregnant females $(n=3)$ may be related to our inability to detect pregnancies. However, both Christian [26] and Dapson [42] had low detection rates of pregnant females from large snap-trapped samples, where pregnancies were determined from autopsy. Dapson suggested that pregnant females may withdraw temporarily from the population and thus move around less. Thus, the low number of pregnant females from our live-trapping study may be an artifact and does not by itself indicate problems with reproduction. Our best evidence for reproduction comes from lactation in females (changes in male breeding condition basically echoing the changes seen in females), and lactation is observed predominantly in spring and summer. The best estimates of female reproduction in the literature come from Dapson's [42] snap-trapping study in the forests of New York; he found that virtually all reproduction was restricted to winter and spring, with very little occurring from July onward. The winter reproduction echoes what Christian [26] found at another site in New York. These finding are generally consistent with ours, though $40 \%$ of our females were still lactating in July and only $12 \%$ by September. Thus, if most of the reproduction in our area is restricted to late winter and spring, production of young would be largely complete by summer, and this should be reflected in population growth. Four of our six populations showed no marked growth from summer to fall, and this may be a reflection of fewer recruits being present in the population (Fig. 2). Though we found no differences in reproduction that could be attributed to PCB effects, we could not determine the precise impact of $\mathrm{PCBs}$ on growth and survival of young born on site. Because Blarina do not enter traps until they are already large [40], a trapping study cannot directly measure on-site production of young or differentiate between animals born on site and those born off the site. However, we found no evidence of differences in growth rate associated with differences in PCB concentrations, and this argues that growth was not affected.

Finally, our study could not directly address the potential impact of maternal PCB loads on the production, survival, and subsequent reproduction of offspring on the floodplain. Two difficulties stand in the way of resolving this. First, periodic flooding clearly prevents continuous, on-site residency of the animals and the floodplains and their adjacent nonflooded lands are involved in a periodic, dynamic interchange of individuals. Second, a characteristic of the biology of Blarina (i.e., young not entering traps until almost full grown) means we cannot know with any degree of certainty where young are born and thus we cannot track their fates and subsequent reproductive histories relative to their maternity. More sophisticated techniques such as the use of mitochondrial and microsatellite DNA analyses would be required to establish maternity.

\section{CONCLUSION}

We found no evidence that variation in PCB concentrations among our trapping grids resulted in differences in population demography of Blarina. Our populations performed at least as well demographically as those living on uncontaminated sites and reported in the scientific literature. Densities were high, survival generally good, and other parameters within the range of the published literature. Thus, despite the presence of PCBs on these floodplains and despite the periodic flooding, these floodplains support healthy and abundant populations of Blarina.

Acknowledgement-This study was funded by the General Electric Company, but all views stated are those of the authors. We wish to thank Ken Fukumoto and Mary Sorensen for assistance with trapping.

\section{REFERENCES}

1. Churchfield S. 1990. The Natural History of Shrews. Christopher Helm, London, UK.

2. George SB, Choate JR, Genoways HH. 1986. Blarina brevicauda. Mamm Species 261:1-9.

3. Whitaker JO Jr, Mumford RE. 1972. Food and ectoparasites of Indiana shrews. J Mammal 53:329-335.

4. Shore RF, Rattner BA, eds. 2001. Ecotoxicology of Wild Mammals. John Wiley, Chichester, UK.

5. Shore RF, Douben PET. 1994. Predicting ecotoxicological impacts of environmental contaminants on terrestrial small mammals. Rev Environ Contam Toxicol 134:49-89.

6. Heida H, Olie K, Prins E. 1986. Selective accumulation of chlorobenzenes, polychlorinated dibenzofurans, and 2,3,7,8-TCDD in wildlife in the Volgermeerpolder, Amsterdam, Holland. Chemosphere 15:1995-2000.

7. Ma W-C, Talmage S. 2001. Insectivora. In Shore RF, Rattner BA, eds, Ecotoxicology of Wild Mammals. John Wiley, Chichester, UK, pp 122-158.

8. Hendriks AJ, Ma W-C, Brouns J, de Ruiter-Dijkman EM, Gast R. 1995. Modelling and monitoring organochlorine and heavy metal accumulation in soils, earthworms, and shrews in Rhinedelta floodplains. Arch Environ Contam Toxicol 29:115-127.

9. Forsyth DJ, Peterle TJ, Bandy LW. 1983. Persistence and transfer of 36Cl-DDT in the soil and biota of an old-field ecosystem: A six-year balance study. Ecology 64:1620-1636.

10. Perkins DW, Hodgman TP, Owen RB, Dimond JB. 1998. Longterm persistence of DDT in shrews, Soricidae, from Maine. Can Field Nat 112:393-399.

11. Ziegler CK. 2003. Quantitative Environmental Analysis, LLC (QEA). General Electric, Pittsfield, MA, USA.

12. Safe SH. 1994. Polychlorinated biphenyls (PCBs): Environmental impact, biochemical and toxic responses, and implication for risk assessment. Crit Rev Toxicol 24:87-149. 
13. Linzey AV. 1988. Effects of chronic polychlorinated biphenyls exposure on growth and reproduction of second generation whitefooted mice (Peromyscus leucopus). Arch Environ Contam Toxicol 17:39-45.

14. McCoy G, Finlay MF, Rhone A, James K, Cobb GP. 1995. Chronic polychlorinated biphenyls exposure on three generations of oldfield mice (Peromyscus polionotus): Effects on reproduction, growth, and body residues. Arch Environ Contam Toxicol 28: 431-435.

15. Sheffield SR, Sawicka-Kapusta K, Cohen JB, Rattner BA. 2001. Rodentia and Lagomorpha. In Shore RF, Rattner BA, eds, Ecotoxicology of Wild Mammals. John Wiley, Chichester, UK, pp 215-314.

16. Linzey AV, Grant DM. 1994. Characteristics of a white-footed mouse (Peromyscus leucopus) population inhabiting a polychlorinated biphenyl contaminated site. Arch Environ Contam Toxicol 27:521-526.

17. Batty J, Leavitt RA, Biondo N, Polin D. 1990. An ecotoxicological study of a population of the white-footed mouse (Peromyscus leucopus) inhabiting a polychlorinated biphenyls-contaminated area. Arch Environ Contam Toxicol 19:283-290.

18. Clark DR Jr, Foerster KS, Marn CM, Hothem RL. 1992. Uptake of environmental contaminants by small mammals in pickleweed habitats at San Francisco Bay, California. Arch Environ Contam Toxicol 22:389-396.

19. TechLaw. 1999. Final Preliminary Ecological Characterization Newell Street to Woods Pond. Boston, MA, USA.

20. ChemRisk. 1994. Evaluation of the Terrestrial Ecosystem of the Housatonic River Valley. Portland, ME, USA.

21. Huang A, Lin S, Inglis R, Powell D, Chou K. 1998. Pre- and postnatal exposure to 3,3',4,4'-tetrachlorobiphenyl: II. Effects on the reproductive capacity and fertilizing ability of eggs in female mice. Arch Environ Contam Toxicol 34:209-214.

22. Getz LL. 1989. A 14-year study of Blarina brevicauda populations in east-central Illinois. J Mammal 70:58-66.

23. Batzli GO. 1977. Population dynamics of the white-footed mouse in floodplain and upland forest. Am Midl Nat 97:18-32.

24. Blair WF. 1939. Some observed effects of stream-valley flooding on mammalian populations in eastern Oklahoma. J Mammal 20: 304-306.

25. Chow VT, Maidment DR, Mays LW. 1988. Applied Hydrology. McGraw Hill, New York, NY, USA.
26. Christian JJ. 1969. Maturation and breeding of Blarina brevicauda in winter. J Mammal 50:272-276.

27. Pollock KH, Nichols JD, Browne C, Hines JE. 1990. Statistical inference for capture-recapture experiments. Wildl Monogr 107: $1-97$.

28. Otis DL, Burnham KP, White GC, Anderson DR. 1978. Statistical inference for capture data from closed populations. Wildl Monogr 62:1-135.

29. Menkens GE, Anderson SH. 1988. Estimation of small-mammal population size. Ecology 69:1952-1959.

30. Krebs CJ. 1966. Demographic changes in fluctuating populations of Microtus californicus. Ecol Monogr 36:239-273.

31. Wauters L, Dhondt AA. 1989. Body weight, longevity and reproductive success in red squirrels (Sciurus vulgaris). J Anim Ecol 58:637-651.

32. Krebs CJ. 2001. Ecology, 5th ed. Benjamin Cummings, San Francisco, CA, USA.

33. Zar JH. 1984. Biostatistical Analysis. Prentice-Hall, Englewood Cliffs, NJ, USA.

34. Sokal RR, Rohlf FJ. 1995. Biometry: the Principles and Practice of Statistics in Biological Research. WH Freeman, New York, NY, USA.

35. Roth J, Haycock K, Gagnon J, Soper C, Caldaroda J. 1994. Statview. Abacus Concepts, Berkeley, CA, USA.

36. SAS Institute. 1994. JMP Statistic and Graphics Guide. Cary, NC, USA.

37. NCSS Statistical Software. 1996. PASS, Ver 6.0. Kaysville, UT, USA.

38. Foster DR. 1999. Thoreau's Country: A Journal Through a Transformed Landscape. Harvard University Press, Cambridge, MA, USA.

39. Platt WJ. 1976. The social organization and territoriality of shorttailed shrew (Blarina brevicauda) populations in old-field habitats. Anim Behav 24:305-313.

40. Getz LL. 1994. Population dynamics of the short-tailed shrew, Blarina brevicauda. In Merritt JF, Kirkland GL, eds, Advances in the Biology of Shrews. Special Publication 18. Carnegie Museum of Natural History, Pittsburgh, PA, USA, pp 27-35.

41. Yahner RH. 1983. Population dynamics of small mammals in farmstead shelterbelts. J Mammal 64:380-386.

42. Dapson RW. 1968. Reproduction and age structure in a population of short-tailed shrews. J Mammal 49:205-21. 